\title{
LUGARES TURÍSTICOS INSTAGRAMÁVEIS: AUTENTICIDADE VIA IMAGEM NA ERA DA SOCIEDADE MIDIÁTICA
}

\author{
Alan Faber do Nascimento *
}

\begin{abstract}
Este ensaio teórico tem como objetivo problematizar o atual desejo social pelas viagens turísticas. Retomando uma tradição crítica presente na sociologia do turismo que anteviu no fenômeno turístico a emergência de uma realidade social cada vez mais imagética e sígnica, a hipótese do trabalho sustenta que o desejo pelas viagens turísticas passou a se pautar pela mesma lógica que caracteriza o consumo na chamada sociedade midiática, a saber: uma prática social tautológica, quase mimética, digitalmente compartilhada, em que não há ideia de surpresa, e na qual o objetivo é, sobretudo, se reconhecer naquilo que os outros turistas estão postando nas redes sociais. É o que se infere de lugares que se transformaram em atrativos turísticos por influência da rede social do Instagram. Para fazer o ensaio, foram utilizadas fontes bibliográficas e dados secundários extraídos de portais eletrônicos de revistas e jornais. 0 ensaio tem orientação teórica baseada no materialismo histórico-dialético.
\end{abstract}

Palavras-chave: Turismo; Redes Sociais; Consumo.

\section{INSTAGRAMABLE TOURIST PLACES: AUTHENTICITY THROUGH IMAGE IN MEDIA SOCIETY ERA}

This theoretical essay aims to problematize the social desire for tourist travel in contemporary times. Resuming a critical tradition in the sociology of tourism that foresaw in the phenomenon the emergence of an increasingly imagetic social reality, the work hypothesis supports the idea that desire for tourist travel shares the same logic that characterizes the so-called midia society: a mimetic social practice, digitally shared, without the idea of surprise, and in which the goal is, especially, to recognize what other tourists are posting on social networks. That is what can be inferred from places made tourist by the influence of the social network of Instagram. To do this essay, bibliographic sources and secondary data extracted from electronic portals of magazines and newspapers were used. The essay has a theoretical orientation based on historical-dialectical materialism.

Keywords: Tourism; Social Networks; Consumption.

\section{SITIOS TURÍSTICOS INSTAGRAMABLES: LA AUTENTICIDAD A TRAVÉS DE LA IMAGEN EN LA SOCIEDAD DE LOS MEDIOS DE COMUNICACIÓN}

Resumen

Este ensayo teórico tiene como objetivo problematizar el actual deseo social de viajes turísticos. Volviendo a una tradición crítica presente en la sociología del turismo que preveía en el fenómeno turístico la aparición de una realidad social cada vez más imaginativa y simbiótica, la hipótesis de trabajo sostiene que el deseo de viajar en turista ha pasado a estar guiado por la misma lógica que caracteriza el consumo en la llamada sociedad de los medios de comunicación, a saber: una práctica social tautológica, casi mimética, digitalmente compartida, en la que no existe la idea de sorpresa y en la que el objetivo es, sobre todo, reconocer lo que otros turistas están publicando en las redes sociales. Esto es lo que surge de los lugares que se han convertido en atracciones turísticas bajo la influencia de la red social de Instagram. Para realizar el ensayo se utilizaron fuentes bibliográficas y datos secundarios extraídos de portales electrónicos de revistas y periódicos. El ensayo tiene una orientación teórica basada en el materialismo histórico-dialéctico.

Palabras clave: Turismo; Redes Sociais; Consumo.

\section{INTRODUÇÃO}

Em 1966, quando Joffre Dumazedier conduzia sua pesquisa na cidade de Annency com 819 operários franceses, para forjar empiricamente um conceito de lazer, chamou-lhe a atenção um dado específico: 0 número de entrevistados que, mesmo tendo condições de fazê-lo, não gostariam de viajar - algo em torno de $40 \%$ da amostra. Resultado que, sem dúvida, desmitificava o que se supunha ser um gosto universal pela viagem, notadamente num momento em que 0 setor turístico ganhava impulso na Europa do pósguerra com as políticas de bem-estar social e pelo desenvolvimento da aviação comercial.

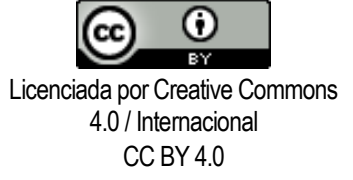

* Graduado em Turismo e mestre em Ciências Sociais (ênfase em Sociologia) pela Pontificia Universidade Católica de São Paulo (2007), doutor em Geografia pela Universidade Estadual Paulista "Júlio de Mesquita Filho", campus Rio Claro (2011), e pós-doutorado em Estudos do Lazer pela Universidade Federal de Minas Gerais (2018). Atualmente é Professor Associado I do curso de Turismo da UFVJM e do mestrado em Estudos Rurais da UFVJM. Tem produção científica nos seguintes temas: Sociologia e História do Turismo; Sociologia do Lazer; Comunidades Tradicionais. Endereço: Rodovia MGT 367 n. 5000 Alto da Jacuba, Gabinete 82, CEP.: 39100 000, Diamantina / MG, Brasil. [alanfaber@uol.com.br ] Lattes iD: http://lattes.cnpq.br/0185442935600199 ; Orcid iD: ? https://orcid.org/0000-0002-4291-2177 
Desde então, passaram-se cinquenta e cinco anos e, a julgar pelo que se observa nas telas digitais de nossa sociedade midiática, difícil acreditar que, se feita hoje, alguma outra enquete do gênero repita os resultados colhidos pelo sociólogo francês.

Alguns dados empíricos fundamentam essas impressões. Em estudo intitulado "10 Principais Tendências Globais de Consumo" para o ano de 2019, realizado pela Euromonitor International, verificou-se que o turismo figura como uma das principais tendências de consumo nas diferentes sociedades do globo (Sampaio, 2019). Em um survey aplicado em Portugal, sobre as intenções de consumo dos portugueses, observou-se que as viagens ocupam o primeiro lugar das preferências. Mais precisamente, $61 \%$ dos inquiridos optaram pelo turismo, ante $43 \%$ que manifestaram a intenção de comprar um eletrodoméstico; $13 \%$ que comprariam um smartphone, e $12 \%$ que desejavam reformar a casa (Antunes, 2019).

E em pesquisa apresentada no fórum da PANROTAS do Brasil, constatou-se que $94 \%$ dos brasileiros têm interesse em turismo. Intitulada de "Turismo, consumo e aeroporto: o super turista brasileiro", a enquete feita com 1599 usuários do principal terminal aeroviário do país, demonstrou que 0 desejo pelas viagens supera 0 de cursar uma faculdade, ou até mesmo o sonho de formar uma família (Martins M., 2019).

Tal subversão de hierarquias não passou em branco entre os observadores das enquetes. $E$ isso não tanto por causa das discrepâncias numéricas, mas pelas mudanças qualitativas que alçaram as viagens ao topo da pirâmide de Maslow. É que, curiosamente, para os respondentes, viajar significa, antes, uma possibilidade de se conectar e poder compartilhar conteúdo nas redes sociais. O raciocínio é o seguinte: numa sociedade em constante transformação pela tecnologia e pela comunicação instantânea, qualquer momento parado, acaba sendo percebido pelas pessoas como tédio. Ato contínuo, sair de casa, conhecer lugares, tirar fotos e poder compartilhá-las nas redes sociais é uma forma de comprovação de que o indivíduo está em movimento.

Talvez isso explique a razão pela qual, para a sociologia do turismo, uma das questões mais intrigantes é imaginar que a atual compulsão pelo movimento se justifique suspostamente porque as viagens turísticas sejam uma experiência original e redentora. Note-se que os próprios analistas da Euromonitor International sugeriram que a primazia pelo turismo na pesquisa se explicava pela necessidade de viagens experimentais, caracterizadas por iniciativas personalizadas, uso de aplicativos, roteiros de "transformação interna" e "experiências autênticas". Nas palavras de um desses analistas: "temos sentido essa transformação, essa busca por viagens que somem na experiência não apenas de turismo, e sim de vida".

Verdade que esse tipo de fala não é uma novidade. Desde os primórdios de sua organização enquanto um setor da indústria cultural, o leitmotiv de agências e operadoras de turismo tem sido as virtudes do anticotidiano - ainda que, invariavelmente, mesmo longe de casa, num desses badalados resorts, o turista se surpreendesse em seu cotidiano. $O$ que é novo, contudo, é inferir que o mundo online, onde cada um pode operar na rede, ao ameaçar a hegemonia do pacote turístico junto com seus clichês de comercialização, teria agora, de fato, desarmado essa ideologia escapista e transformado a viagem numa possibilidade de experiência real (no sentido de uma prática social desideologizada) para quem a desfruta.

Essa é uma questão para a qual os sociólogos da área não podem se abster. Afinal, se seguirmos a opinião alheia, como explicar, então, as situações em que o desejo de viajar tem sido marcado mais pela vontade de se reconhecer naquilo que está sendo compartilhado nas redes sociais do que propriamente em se surpreender por algo que não se sabe, não se conhece ou não se viu? Não seria, então, o caso de atualizar a crítica sociológica do fenômeno e levá-la às últimas consequências: a de que o turismo não provoca surpresas?

\section{A NOVA LÓGICA DO CONSUMO NA SOCIEDADE MIDIÁTICA}

A chamada sociedade midiática revolucionou a maneira de despertar o desejo para o consumo nas pessoas. Nesse âmbito da vida social, tem se visto um novo modus operandi, cuja origem nos remete à reestruturação produtiva do capital e à globalização tecnológica do final do século XX, e que se distingue tanto dos métodos de propaganda aplicados na origem do industrialismo do século XIX quanto da publicidade do pós-guerra, voltada para um mercado de massas.

Historicamente, é difícil situar com precisão a origem da propaganda publicitária. No Ancien Regime, ela se resumia ao charlatanismo. 0 objetivo dos anúncios era enganar clientes adulterando informações dos produtos, usualmente expostos sem qualquer interesse pela sedução.

Mais adiante, na passagem da produção artesanal para a grande indústria, já se observam alguns sinais de que é preciso seduzir o consumidor, muito embora a ênfase na racionalização da produção acabava por eclipsar o problema do consumo, relegando-o a um segundo plano. Com efeito, a propaganda será tão austera quanto 0 ethos 
protestante da nova economia: na maioria das vezes, concisa e baseada nas propriedades funcionais dos produtos (Ortiz, 1991).

A forma da publicidade se modifica substancialmente no momento em que o sistema produtivo se desloca para a produção ilimitada de bens. $O$ resultado é que a publicidade deixa de ser descritiva para se tornar sugestiva: "os produtos são lançados antes mesmo que a vontade em adquiri-los se manifeste" (Ortiz, 1991: 175). Em consequência, o método para despertar o desejo pela compra no consumidor ganha feições psicanalíticas e a cargo dele se ocuparão especialistas e institutos com a missão de transformar a mercadoria numa promessa, ainda que ilusória, daquilo que nos falta. É o que François Brune (apud Padilha, 2006) classificará como as sete funções ideológicas da publicidade moderna, a saber: reduzir, frustrar, erotizar, alienar, recuperar, empoderar e infantilizar.

A indústria do tabaco é um exemplo paradigmático do fazer publicitário moderno. Nos anos 1920, os fabricantes de cigarro nos Estados Unidos se queixavam da alta taxa de ociosidade de suas unidades produtivas, devido ao fato de que metade de seus potenciais consumidores estavam impedidos de fumar. Eles se referiam ao tabu que maldizia as mulheres que fumavam. Numa década notabilizada pela luta feminina, não tardou para que os publicitários enxergassem na censura moral um álibi para promover o cigarro ao status de "tocha da liberdade". A ideia ganhou vida num famoso desfile de moda feito durante o tradicional Thanksgiving Day. À época, arquitetado por um dos expoentes do ramo, o austro-americano Edward Bernays, o plano era o seguinte: no meio do desfile as mulheres (no caso, feministas convidadas) deveriam sacar de chofre os cigarros dos seus bolsos e começar a fumar perante todos os convidados. Esse episódio é um marco do uso das relações públicas para promover um produto e teve profundas implicações na generalização dos fumantes na sociedade americana - algo semelhante aconteceu, posteriormente, com os homens. Nos anos 1950, os cigarros com o filtro eram considerados afeminados. Foi aí que se teve a ideia de associar o seu consumo com o que havia de mais másculo no imaginário coletivo do americano médio, o cowboy. Dessa operação, catalisada pela televisão e por Hollywood, nasceu um ícone da indústria cultural do pós-guerra, o Marlboro Man (Fontenelle, 2014).

Além da propaganda-ilusão, outro procedimento adotado para impulsionar o consumo de massas foi a chamada "experiência do lugar" que a imagem da marca do produto oferece. Tal expediente consiste em oferecer doses de anticotidiano para amenizar o dia a dia que assola os habitantes das cidades geradas pela indústria. Assim, ao contrário do que na antiguidade os filósofos prescreviam, quando se dizia que "era de alma que se precisava mudar, e não de clima", a publicidade moderna espacializou o consumo ao transformá-lo num oásis em meio ao caos. Tal redenção é, sistematicamente, utilizada pelos diversos setores da economia, da indústria automobilística ao trade turístico.

À vista desses dois procedimentos adotados pela publicidade moderna, seria o caso de se perguntar se eles ainda se sustentam, haja vista situações indicativas de que estejamos diante de um novo modo de relacionamento entre consumo, publicidade e consumidor. É em que se apoia Lipovetsky (2005) ao mostrar como a publicidade pós-moderna adotou um tom irônico, satírico, aparentemente niilista, em relação a suas promessas e seduções passadas. Tudo se passa como se a imagem fetichista perdesse credibilidade diante de uma realidade que se tornou cada vez mais transparente, desideologizada. Um exemplo é o mercado cervejeiro, cujas campanhas de marketing, caso da marca Heineken, têm se notabilizado por satirizar os lugares-comuns empregados pelo setor.

Tampouco a estratégia da "experiência do lugar" parece gerar algum tipo de convencimento - ainda que, no plano discursivo, continue sendo utilizada. Se assim o fosse, como explicar o sucesso de lugares de consumo em que o grande atrativo é a circulação rápida em espaços totalmente funcionais, caso dos outlets, arquétipos daquilo que a antropologia definiu como não-lugares?

Como possibilidade de resposta, não parece apropriado investir na hipótese de estejamos diante do fim do espetáculo. Longe de ter se tornado transparente, a realidade produzida pela globalização econômica e tecnológica do capital parece fundir o real com a representação, de modo a não haver mais nenhuma separação entre eles. Isso significa dizer que a própria realidade virou um espetáculo. Em chave marxista, diríamos que a relação fetichista entre coisas que encobre relações reais entre homens assume uma feição ainda mais fetichizada. Trata-se agora de uma relação entre a imagem das coisas (Fontenelle, 2013). Eis o sentido preciso em definir esta sociedade como midiática.

\section{A NATUREZA IMAGÉTICA DO TURISMO NA TRADIÇÃO CRÍTICA SOCIOLÓGICA: ATUALIZANDO ALGUMAS QUESTÕES}

Historicamente, um setor que prenunciou essas transformações foi o das viagens turísticas. Em 1962, Daniel Boorstin as antevê em seu clássico The Image. Nesse trabalho, o turismo é um arquétipo de um momento histórico em que a representação, 
paradoxalmente, se torna mais real do que a própria realidade (Boorstin, 1992). Malgrado, nessa época, o autor estivesse mais interessado em sublinhar a perda da arte de viajar, no turista que "mata" a experiência do viajante, do que propriamente com questões da pósmodernidade, cumpre observar que, ainda nos estágios iniciais do processo, o turismo já apareça como um caso modelo.

Igualmente significativo é que, entre os anos 1970 e 1990, coincidindo com o boom dos fluxos turísticos globais, sobrevém toda uma tradição teórica dedicada a explorar a natureza imagética das viagens turísticas. Em The Golden Hordes, Louis Turner e John Ash dizem que os lugares turísticos são um pequeno mundo monótono que, em todos os lugares, nos mostra a nossa própria imagem (Turner \& Ash, 1975). Em L'image touristique comme introduction à la geographie du tourisme, Jean Marie Miossec define o espaço turístico, sobretudo, como uma imagem (Miossec, 1977). Em Semiocts of Tourism, Jonathan Culler compara os turistas a um exército de semióticos à procura de signos de francesismo, de comportamento típico italiano, de clichês do orientalismo, das inveteradas autopistas americanas e dos tradicionais pubs ingleses (Culler, 1981). E, em The Tourist Gaze, John Urry observa que o olhar do turista é, por natureza, não-aurático, de modo que absolutamente tudo, independente do espaço e do tempo, pode ser objeto de sua curiosidade: "quando os turistas veem duas pessoas se beijando em Paris, 0 que seu olhar capta é uma Paris intemporal em seu romantismo" (Urry, 1999: 18).

Em síntese, o mérito desses trabalhos foi ter antecipado a estrutura sígnica que passou a determinar a experiência do turismo contemporâneo. A esse propósito, tem razão Ortiz (2000) ao afirmar que uma das principais consequências da globalização foi o desenraizamento das referências culturais para que pudessem operar como signos de um imagináriomundo. Desse modo, os espaços turísticos, outrora difamados pela pecha da estandardização, paradoxalmente, se converteram numa extensão de nossos lares. É que tais espaços, por mais vazios que sejam, estão tão preenchidos de signos que, aos olhos do turista-consumidor, ficam plenamente legíveis.

O enredo do filme 0 Terminal nos dá uma boa ideia do que se mudou em relação ao turismo de massas. O longa-metragem narra a história de Viktor Narvoski, cidadão da fictícia Krakozhia, que, devido a um impasse diplomático, termina preso num aeroporto de Nova York. No caso, o dilema de Viktor não é porque ele está impedido de voltar para casa, tampouco por não conseguir pisar em solo americano, e sim porque se encontra desterritorializado. Afinal, Viktor precisa começar a viver num espaço, essencialmente, funcional, marcado pela despersonalização das relações e onde, à primeira vista, é impossível deitar raízes - ainda que, ao longo do confinamento, Viktor, pouco a pouco, vai transformando em lugar o que antes era um não-lugar: cria uma rotina; arranja amigos e desafetos; constrói um quarto no subsolo do aeroporto, e inclusive se apaixona por uma aeromoça.

O que aconteceria, entretanto, se Viktor não fosse natural de Krakozhia; mas, sim, um cidadão francês, inglês, brasileiro, ou mesmo um nativo da China - atualmente tão ocidentalizada? Ficaria esse sujeito comum desorientado e sem um sentido de lugar no interior de um aeroporto? Ou melhor, hoje, onde nos sentimos mais familiarizados, no lobby de um hotel do grupo Accor ou nos labirínticos becos de uma cidade histórica?

A questão é que o modus operandi do turismo na sociedade midiática problematiza determinadas interpretações que buscaram relativizar a essência sígnica do consumo turístico. Tornou-se, no mínimo, controversa a ideia de que o turista busca em suas viagens um contato com 0 autêntico - porém, é fraudado em suas intenções pelas promessas publicitárias das agências de turismo, bem como pelo senso de autopreservação das populações autóctones, interessadas em oferecer aos que vêm de fora uma fachada para preservar os bastidores de um modo de vida. 0 mesmo se aplica à visão de que 0 turista na pós-modernidade se tornou um agente cônscio do jogo de encenação em que está inserido e mesmo assim, à maneira irônica ou satírica, topa jogá-lo. Em suma, conceitos como o de "autenticidade encenada" ou do "pós-turista" parecem ter pouco valor heurístico num tempo histórico em que o principal atrativo de uma viagem, sublinhe-se, é se reconhecer naquilo que já se sabe.

Nas atuais viagens turísticas não há, portanto, fuga ao anticotidiano, tampouco a ilusão de um mergulho numa realidade feérica; pelo contrário, nessas viagens, tudo é costumeiro e não existem surpresas - nelas, somos nostálgicos pelo presente (Jameson, 1996). Os lugares turísticos são, assim, um espaço de rememoração que nos aprisiona a um presente onde passado e futuro estão fundidos na familiaridade de "objetos-signos", e no qual "ao nos movimentarmos percebemos que nos encontramos no mesmo lugar" (Ortiz, 2000: 134).

\section{A COMPULSÃO PELO MOVIMENTO E OS LUGARES TURÍSTICOS INSTAGRAMÁVEIS}

Os lugares turísticos promovidos pelo compartilhamento de fotos no Instagram, talvez, sintetizem as mudanças que afetaram a experiência da 
viagem nos dias de hoje. Um caso típico é o templo de Pura Lempuyang na Indonésia. De lugar até pouco desconhecido no circuito turístico global, o destino virou uma obsessão, a ponto de haver filas para se conseguir uma selfie com a edificação ao fundo (Martinez, 2019).

Outro exemplo é a praia Maya Bay, palco das filmagens do filme A Praia estrelado por Leonardo de Capri e cujo acesso em 2018 foi fechado a pedido das autoridades locais, para que o ecossistema local pudesse se recuperar dos impactos provocados pelas multidões de visitantes (Martins V., 2018). A pedra do Telégrafo, situada no cume do Morro de Guaratiba, no Rio de Janeiro, também, se encaixa nesse novo perfil de atrativos turísticos. Os estimados 1.500 visitantes que, por dia, buscam escalá-la o fazem menos pela adrenalina do que pela possibilidade de se exibir perante seus públicos virtuais - como atesta o frisson gerado após um jogador de um grande clube do futebol carioca postar uma foto no Instagram em que aparece pendurado na pedra beijando a esposa como prova de amor (Araujo, 2016). E, mais recentemente, uma escadaria no distrito do Bronx, usada por Joaquim Phoenix em cena performática de 0 Coringa, tornouse lugar obrigatório para quem vai visitar a Big Apple. Tanto que a hashtag \#jokerstairs tem sido tão eficiente em promover o turismo na cidade quanto os guias de passeio e folhetos locais (Maia, 2019).

É digno de nota a natureza instantânea dessa nova classe de atrativos turísticos. Afinal, lugares até então prosaicos se convertem da noite para o dia em ícones do entretenimento e do lazer. Em pesquisa feita em 2015 pelo sítio eletrônico Miss Travel com 78 mil usuários do Instagram, constatou-se que $48 \%$ dos entrevistados utilizavam a rede para a escolha do destino de viagem; ao passo que $35 \%$ a usavam para descobrir novos lugares (Cohen, 2015).

Em 2017, num estudo realizado por uma empresa britânica de seguros de viagens, verificou-se que $40 \%$ dos chamados millennialls apontam que a principal motivação para a escolha do destino da viagem é o quão "instagramável" o lugar é - ante $24 \%$ que priorizam custos e disponibilidade de bebidas alcoólicas, $22,6 \%$ que optam pelo desenvolvimento pessoal, 9,4\% que dão preferência à culinária local, e $3,9 \%$ que buscam oportunidades de paisagem (Revista Forbes, 2020).

Em enquete conduzida pelo sítio eletrônico de reservas Hoteís.com em 2019, demonstrou-se que, no Brasil, o Instagram é determinante para $41,1 \%$ dos 500 turistas participantes da pesquisa. A investigação, ainda, aponta que, na hora de realizar uma foto da viagem, $55 \%$ usam o timer do celular para realizar o disparo, $45 \%$ pedem a ajuda de terceiros; $34 \%$ alegam passar horas editando as fotos; $36 \%$ topariam pagar um fotógrafo profissional para tirar fotos da viagem ou que acordariam logo pela manhã para evitar multidões e conseguir a melhor iluminação (Brasilturis Jornal, 2019).

As empresas globais do trade turístico, as municipalidades locais e órgãos institucionais já perceberam, tanto para o bem quanto para o mal, 0 quanto a selfie tem sido determinante na turistificação dos lugares. A Airbnb, gigante do setor de aplicativos de hospedagem compartilhada, conta em seu perfil no Instagram com mais de 3 milhões de seguidores. A pequena cidade nova-zelandesa de Wanaka, exemplo sobre o trabalho de engajamento nas redes sociais e uso de influenciadores digitais em destinos turísticos, conseguiu alavancar os números do turismo local em $14 \%$. Por outro lado, as cidades da Islândia têm convivido com inúmeros problemas ambientais e conflitos culturais decorrentes de fluxos instantâneos de visitantes - também pudera: estima-se em 10 milhões o número de fotos compartilhadas do país no Instagram (Willians, 2019).

Dentre outros exemplos, vale ainda mencionar o da Agência Brasileira de Promoção Internacional do Turismo (EMBRATUR). Em 2014, esse órgão estatal responsável pela comercialização da imagem turística do país no exterior contratou o russo Murad Osmann, a fim de que ele fotografasse os principais cartões postais das cidades brasileiras. À época, a ação resultou num aumento de $189 \%$ de seguidores do perfil Visit Brasil no Instagram. Nesse episódio, o que surpreende, no entanto, é que o motivo do convite não foi tanto pelo talento profissional do fotógrafo, e sim porque Murad Osmann se consagrou nas redes sociais compartilhando fotos de sua namorada, em viagens pelo mundo, sempre na mesma perspectiva, qual seja: no centro da foto, de costas e de mãos dadas com ele (Lima, 2014).

O curioso é que alguns analistas do fenômeno apontem que 0 sucesso dos lugares turísticos instagramáveis se deve a um desejo por imagens mais autênticas, em oposição àquelas que, habitualmente, figuram em revistas especializadas e na propaganda turística. Terttunen (2017) observa que vídeos e fotos compartilhados oferecem um senso de autenticidade real sobre o destino a ser visitado. 0 que é importante na hora de se decidir por este ou aquele produto turístico, uma vez que a sua intangibilidade não permite que ele seja apreciado a priori. Já Baumann (2015) constata que aspectos que usualmente se associam a práticas turísticas alternativas e sustentáveis, como estilo de vida, cultura, tradição e patrimônio, são essenciais nas imagens percebidas e compartilhadas pelos turistas - havendo inclusive, por parte deles, um enfoque para o que é a essência do lugar. 
De fato, na sociedade midiática, entre as diversas formas de se promover um produto, a chamada mídiarealidade, aquela que, teoricamente, deve expressar "a coisa verdadeira", alcançou a hegemonia (Fontenelle, 2013). Não que isso seja uma novidade da era digital. Basta lembrar, como se viu, que a quebra do tabu e o hábito de fumar entre as mulheres americanas a partir da década de 1920 ocorreu segundo esses meios. No entanto, o que antes das redes sociais era uma heterodoxia, tornou-se uma regra: estima-se que $92 \%$ dos consumidores em todo o mundo afirmam confiar mais no vulgo "boca a boca eletrônico" e na recomendação de amigos e da família do que nas formas tradicionais de publicidade (Terttunen, 2017).

É igualmente verdade que, na promoção turística, tais expedientes já foram vistos no cinema. Como não lembrar de 0 fabuloso destino de Amélie Poulain? Até porque o bairro francês de Montmartre acabou por se tornar, desde então, um ponto de peregrinação de multidões de curiosos. E o que dizer dos estimados seis milhões de turistas que visitam o museu do Louvre anualmente? Boa parte deles não querem emular os passos do investigador Robert Langdon, em O Código da Vinci?

Ocorre, no entanto, que os lugares turísticos instagramáveis apresentam uma singularidade que não concorre com nenhuma outra turistificação congênere, a saber: não raras vezes, as imagens compartilhadas das viagens são manipuladas. A já clássica selfie perante o templo indonésio de Pura Lempuyang é resultado de um truque: para simular um espelho d'água sobre 0 qual o turista parece flutuar coloca-se um espelho ou uma superfície refletora na parte inferior da lente da câmera. A prova de amor exibida nas redes sociais por quem se arrisca nas alturas da pedra do Telégrafo é resultado de uma ilusão de ótica. Para tê-la, basta posicionar 0 equipamento fotográfico no ângulo certo. E mesmo a praia de Maya Bay, de paisagem exótica e desabitada pelo que foi visto no cinema, convive com os mesmos problemas do velho turismo de sol, praia e mar, a julgar pela fala de um turista que recentemente a visitou: "estava fazendo uma foto da minha namorada no mar, quando percebi que isso era feito por todos os demais namorados do Instagram".

À luz dessas revelações, seria um engano classificar tais imagens como falsas, à maneira de um pseudo-evento. A um só tempo, possuem e não razão os que atribuem à autenticidade o motivo por que os lugares turísticos instagramáveis são um sucesso. É que o "autêntico" na sociedade midiática passou a ser sinônimo da imagem que nos faz ser notados e, assim, amealharmos seguidores. Esse é o saldo de uma sociedade em que tudo na vida se apropria de técnicas de relações públicas para poder existir; onde cada um de nós se transforma num meio pelo qual o consumo se realiza - um estágio em que, para sermos consumidores, devemos antes nos tornar mercadorias (Bauman, 2008). Daí que, em vez de uma experiência marcada pela ideia de mudança e transformação, esses lugares tornados turísticos pelas redes sociais expressam, antes, uma ansiedade generalizada para que não sejamos deixados para trás em pleno movimento.

Assim, o turismo, não importa qual o tipo, de massas, convencional, alternativo, se torna, de fato, uma prática social massificada, porquanto se converte em algo tautológico, como se fosse um meme: eu desejo viajar porque todo mundo ou grande parte das pessoas parece estar viajando. De modo que as promessas que a modernidade conferiu às viagens turísticas parecem ter sido de alguma forma total ou parcialmente suplantadas. Não se trata mais de descobrimento, status ou recuperação física e psíquica do indivíduo; o "preciso tirar umas férias" se transmutou agora numa espécie de desabafo narcísico de um "eu" premido pela tarefa de se reinventar constantemente para se apresentar ao mundo - digase, tornar-se vendável.

Discorrendo de um belvedere em que a internet, todavia, principiava a transformar a forma de nos comunicarmos, e as redes sociais nem sequer existiam, Carol Crawshaw e John Urry (1997) definiram, de forma sagaz, o turismo como a mercantilização das recordações do outro. À vista do exposto, talvez atualizaríamos a definição, para um hábito, digamos, menos analógico. Afinal, nesses tempos em que todos estamos, online, compartilhando nas redes sociais a nossa mais nova experiência turística, qual o sentido que ainda há em rituais de congraçamento em torno de álbuns de família?

\section{REFERÊNCIAS}

Antunes, C. (2019). Portugueses querem viajar mais mas também aumentar as poupanças em 2019. Expresso. Lisboa, 15 abr. 2019. Disponível em: <https://amp.expresso.pt/economia/2019-04-15-

Portugueses-querem-viajar-mais-mas-tambemaumentar-as-poupancas-em-2019> Acesso em: 27 mar. 2020

Araujo, A. (2016). Cenário de Selfies, pedra do telégrafo padece com maus turistas. Jornal O Dia. Brasil, 09 jan. $2016 . \quad$ Disponível em: <https://odia.ig.com.br/_conteudo/2016-01-10/cenariode-selfies-pedra-do-telegrafo-padece-com-mausturistas.html> Acesso em: 06 fev. 2020.

Bauman, Z. (2008). Vida para Consumo: a transformação das pessoas em mercadoria. São Paulo, Zahar.

Baumann, F. (2015). Análise da imagem projetada e percebida do destino Lisboa através da fotografia digital: a rede Instagram como nova resposta para a recolha de 
dados. 112 f. [Dissertação - Mestrado em Marketing e Promoção Turística]. Instituto Politécnico de Leiria Escola Superior de Turismo e Tecnologia do Mar, Peniche.

Boorstin, D. (1992). The Image: A Guide to Pseudo-Events in America. Nova York, Vintage Books.

Brasilturis Jornal. (2019). Estudo mostra que turistas supervalorizam postagem de fotos no Instagram. Brasilturis Jornal. Brasil, 10 mai. 2019. Disponível em: $<$ https://brasilturis.com.br/estudo-mostra-que-turistassupervalorizam-postagem-de-fotos-no-instagram/> Acesso em 07 fev. 2020.

Cohen, D. (2015). Instagram Is the Modern-Day Travel Agent. Adweek. Nova York, 17 nov. 2015. Disponível em: <http://www.adweek.com/digital/misstravel-instagramtravel-survey/> Acesso em 07 fev. 2020.

Crawshaw, C. \& Urry, J. (1997). Tourism and the photographic eye. In: Rojek, C. \& Urry, J. (orgs.) Touring cultures: transformations of travel and theory. Londres, Routledge, pp. 176 - 195.

Culler, J. (1981). The Semiotics of tourism. The American Journal of Semiotics, Virginia, v. 1, pp. 127 - 140.

Fontenelle, I. A. (2013). O nome da marca: McDonald's, fetichismo e cultura descartável. São Paulo, Boitempo.

Fontenelle, I. A. (2014). A Cultura Política do Consumo. Instituto Vox de Pesquisa em Psicanálise. Brasil, 26 nov. $2014 . \quad$ Disponível em: https://www.youtube.com/watch?v=as3ySZ RYsE Acesso em: 23 nov. 2020.

Jameson, F. (1996). Pós-modernismo: a lógica cultural do capitalismo tardio. São Paulo, Ática.

Lima, R. (2014). Depois de ação, Instagram da Embratur aumentou $189 \%$ em número de seguidores. Brasilturis Jornal. Brasil, 28 ago. 2014. Disponivel em: $<$ https://brasilturis.com.br/depois-de-acao-instagramda-embratur-aumentou-189/> Acesso em 07 fev. 2020.

Lipovetsky, G. (2005). A era do vazio: ensaio sobre o individualismo contemporâneo. São Paulo, Manole.

Maia, E. (2019). Escadaria do filme "Coringa" é a mais nova atração turística de Nova York. Jornal O Globo. Rio de Janeiro, 27 out. 2019. Disponível em: <https://oglobo.globo.com/boa-viagem/escadaria-dofilme-coringa-a-mais-nova-atracao-turistica-em-novayork-1-24043553> Acesso em 06 fev. 2020.

Martinez, H. L. (2019). O turismo com fotos falsas que exige horas de fila para fazer uma imagem fake num templo de Dubai. El País. Brasil, 09 jul. 2019. Disponível em:

<https://brasil.elpais.com/brasil/2019/07/05/actualidad/15623 31846 946560.html> Acesso em: 05 fev. 2020.
Martins, M. (2019). Estudo inédito: 94\% dos brasileiros têm interesse em viagens. Panrotas. Brasil, 20 mar. 2019. Disponivel em: $<$ https://www.panrotas.com.br/mercado/pesquisas-eestatisticas/2019/03/estudo-inedito-94-dos-brasileirostem-interesse-em-viagens_163113.html> Acesso em: 27 mar. 2020.

Martins, V. (2018). Praia do Dicaprio: Maya Bay fechada por tempo indeterminado. Revista Viagem. São Paulo, 23 fev. $2018 . \quad$ Disponível em: <https://viagemeturismo.abril.com.br/materias/praia-dodicaprio-maya-bay-restringira-acesso-na-baixatemporada/> Acesso em: 06 fev. 2020.

Miossec, J. M. (1977). L'image touristique comme introduction à la geografie du tourisme. Paris: Annales de Geographie, 1977.

Ortiz, R. (1991). Cultura e Modernidade. São Paulo, Brasiliense.

Ortiz, R. (2000). Mundialização e Cultura. São Paulo, Brasiliense.

Padilha, V. (2006). Shopping Center. a catedral das mercadorias. São Paulo, Boitempo.

Revista Forbes. (2020). Como o Instagram está remodelando o turismo. Revista Forbes Brasil. Brasil, 03 fev. 2020. Disponível

em: $<$ https://forbes.com.br/fotos/2018/02/como-oinstagram-esta-remodelando-o-turismo/> Acesso em 07 fev. 2020.

Sampaio, V. (2019). Turismo está entre as tendências globais de consumo em 2019. Portal do Ministério do Turismo. Brasil, 13 fev. 2019. Disponível em: $<$ <ttp://www.turismo.gov.br/\%C3\%BAltimasnot\%C3\%ADcias/12406-turismo-est $\%$ C3\%A1-entreas-10-tend\%C3\%AAncias-globais-de-consumo-em2019.html> Acesso em: 27 mar. 2020.

Terttunen, A. (2017). The Influence of Instagram on consumers' travel planning and destination choice. 83p. [Tese de Doutorado] Program Hospitality, Tourism and Experience Management (Haaga-Helia University of apllied sciences), Finlândia.

Turner, L. \& Ash, J. (1975). The Golden Hordes: International Tourism and the Pleasure Periphery. Londres, Constable.

Urry, J. (1999). O olhar do turista. São Paulo, Studio Nobel.

Willians, S. (2019). Por que os irlandeses não aguentam mais os influencers do Instagram. BBC News. Brasil, 26 jun. 2019. Disponível em: <https://www.bbc.com/portuguese/geral-48745158> Acesso em 07 fev. 2020.

Processo Editorial / Editorial Process / Proceso Editorial

Editor Chefe / Editor-in-chief / Editor Jefe: PhD Thiago D. Pimentel (UFJF).

Recebido / Received / Recibido: 02.04.2020; Revisado / Revised / Revisado: 10.12.2020; Aprovado / Approved / Aprobado: 10.12. 2020; Publicado / Published / Publicado (online): 12.12.2020.

Artigo original / Original paper / Artículo original.

Seção não revisada às cegas por pares / No double blind review section / Sessión no revisada por pares ciegos. 